\title{
PROPRIEDADES REOLÓGICAS DA POLPA DE MANGA (Mangifera indica L. cv. Keitt) CENTRIFUGADA
}

\author{
Rheological properties of centrifuged mango (Mangifera indica L. cv. Keitt) pulp
}

\author{
José Raniere Mazile Bezerra Vidal', Maria-Rita Sierakowski², \\ Charles Windson Isidoro Haminiuk ${ }^{3}$, Maria Lúcia Masson ${ }^{4}$
}

\begin{abstract}
RESUMO
Objetivou-se com este trabalho estudar experimentalmente o comportamento reológico da polpa de manga centrifugada na faixa de temperatura de $10^{\circ} \mathrm{C}$ a $60^{\circ} \mathrm{C}$. As medidas reológicas foram feitas no reômetro Haake Rotovisco modelo RV - 20, utilizando o sistema de medida de cilindros concêntricos. A polpa integral foi produzida em uma despolpadeira com tela de 1,6 mm, congelada em um congelador de placas e armazenada a $-15^{\circ} \mathrm{C}$ e centrifugada a $15000 \mathrm{rpm}(29000 \mathrm{G})$, durante 40 minutos. O comportamento reológico da polpa de manga centrifugada (reogramas) foi ajustado pelo modelo de Ostwald de Waelle (Lei da Potência) e as curvas de viscosidade aparente ajustadas pelo modelo de Mizrahi-Berk. Observou-se um comportamento pseudoplástico para a polpa de manga centriguda $(n<1)$ e uma diminuição na viscosidade aparente com o aumento da taxa de deformação e temperatura, sendo que a viscosidade aparente da polpa de manga centrifugada tendeu a ficar constante a partir $200 \mathrm{~s}^{-1}$.
\end{abstract}

Termos para indexação: Reologia, temperatura, manga, polpa.

\begin{abstract}
The aim of this work was to study experimentally the rheological behavior of mango pulp centrifuged in a temperature range of 10 to $60^{\circ} \mathrm{C}$. The rheological measurements were carried out in a rheometer Haake Rotovisco model RV-20, using a measuring system of concentric cylinders. The whole pulp was produced in a depulper with a 1,6mm screen, being plate-frozen and stored at $-15^{\circ} \mathrm{C}$ and it was centrifuged at $15000 \mathrm{rpm}(29000 \mathrm{G})$ during 40 minutes. The rheological behavior of the centrifuged mango pulp was fitted to the Ostwald de Waelle model (Power Law) and the apparent viscosity curves were fitted by the Mizrahi-Berk model. It was observed a shear thinning behavior to the centrifuged mango pulp $(\mathrm{n}<1)$ and a decrease in apparent viscosity with an increase in shear rate and temperature, whereas the apparent viscosity of the centrifuged mango pulp had a tendency to stay steady up to $200 \mathrm{~s}^{-1}$.
\end{abstract}

Index terms: Rheology, temperature, mango, pulp.

(Recebido para publicação em 20 de outubro de 2005 e aprovado em 10 de abril de 2006)

\section{INTRODUÇÃO}

A manga é um fruto de regiões tropicais e subtropicais de grande demanda em todo o mundo, tanto para o seu consumo "in natura" quanto industrializada na forma de sucos, néctares, sorvetes e sobremesas gelificadas (PELEGRINE, 1999). A cultivar Keitt ocupa posição de destaque nos mercados interno e externo, tanto para o consumo "in natura" quanto para a industrialização, conforme relatam os trabalhos de Cerezal et al. (1995) e Siqueira et al. (1988), devido ao elevado teor de polpa e de sólidos solúveis totais, maior suculência e menor teor de fibras.

Para fabricação dos produtos derivados de manga utiliza-se a polpa integral, a qual é submetida a vários processos de industrialização. Para que cada etapa do processo seja economicamente viável, é fundamental o conhecimento das propriedades físicas e químicas da polpa. Dentre essas propriedades, o comportamento reológico ocupa posição de grande destaque, sendo útil não só como medida de qualidade, mas também em projetos, avaliação e operação dos equipamentos processadores de alimentos, tais como as bombas, sistemas de agitação e tubulações (IBARZ et al., 1996; QUEIROZ et al., 1996).

As medidas reológicas são consideradas como uma ferramenta analítica, a qual fornece uma melhor compreensão da organização estrutural dos alimentos. Vários fatores afetam o comportamento reológico das polpas de frutas, destacando-se entre estes, a temperatura (HOLDSWORTH, 1971; VITALI et al., 1984), sólidos solúveis (HERNANDEZ et al., 1995) e o tamanho das partículas (AHMED et al., 2000).

Diversos estudos têm mostrado que as polpas de frutas comportam-se como um fluído pseudoplástico, como

\footnotetext{
${ }^{1}$ Engenheiro de Alimentos, Professor Dr. do Departamento de Engenharia de Alimentos - Universidade Estadual do Centro-Oeste - Cx. P. 730 Guarapuava, PR - raniere@unicentro.br

${ }^{2}$ Farmacêutica Bioquímica - Professora Dra. Laboratório de Biopolímeros - Universidade Federal do Paraná - Cx. P. 19081 - Curitiba, PR mariarita.sierakowski@ufpr.br

${ }^{3}$ Engenheiro de Alimentos, M.Sc, Doutorando do Programa de Pós-Graduação em Tecnologia de Alimentos - Universidade Federal do Paraná Cx.P. 19011 - Curitiba, PR - chaminiuk@yahoo.com

${ }^{4}$ Engenheira Química, Professora Dra. do Programa de Pós-Graduação em Tecnologia de Alimentos - Universidade Federal do Paraná - Cx. P. 19011 Curitiba, PR - masson@ufpr.br
} 
resultado de complexas interações entre os açúcares solúveis, substâncias pécticas e sólidos suspensos (AHMED et al., 2005). Estudos anteriores mostram que a polpa de manga integral, apresenta um comportamento pseudoplástico (AHMED et al., 2005; PELEGRINE et al., 2000, 2002). Embora a reologia da polpa de manga integral tenha sido estudada por vários pesquisadores (BHATTACHARYA \& RASTOGI, 1999; MANOHAR et al., 1990; PELEGRINE et al., 2002), estudos a respeito da polpa sem os sólidos suspensos ainda não foram realizados.

Levando em consideração os diversos estudos com a polpa de manga integral, o objetivo deste trabalho foi estudar experimentalmente o comportamento reológico da polpa de manga centrifugada, ou seja, sem partículas em suspensão, na faixa de temperatura de $10^{\circ} \mathrm{C}$ a $60^{\circ} \mathrm{C}$, tendo em vista que a polpa nesta condição se assemelha muito ao suco de manga.

\section{MATERIAIS E MÉTODOS}

\section{Preparo da Amostra}

A manga utilizada neste trabalho é da cultivar Keitt e foi selecionada de um único lote proveniente da região sul de Minas Gerais. A polpa foi produzida em uma despolpadeira (marca Mecamau) utilizando uma tela com abertura de 1,6 mm. O teste de maturação dos frutos foi realizado utilizando-se um texturômetro da marca Texture Analyser modelo TA - TX2. A escolha da ponta de prova e a profundidade de penetração na superfície da amostra foi feita de maneira que os testes se aproximassem o máximo possível da avaliação realizada pelos dedos humanos quando se estima o grau de maturação de uma fruta pela apalpação. Dentre as pontas de prova disponíveis no equipamento, foi escolhida uma ponta circular plana com $1,0 \mathrm{~cm}^{2}$ de área, sendo que nos teste foi fixada uma penetração de $5 \mathrm{~mm}$ e utilizados 10 frutos inteiros.

A polpa integral foi congelada em um congelador de placas a $-20^{\circ} \mathrm{C}$, visando um congelamento rápido do material para evitar a formação de grandes cristais de gelo na superfície e danificação das estruturas celulares, além de inibir ações enzimáticas. Após 4 horas, o material foi retirado e embalado a vácuo em sacos de polietileno para diminuir o contato com o ar. O produto embalado foi armazenado em freezer horizontal $\mathrm{a}-15^{\circ} \mathrm{C}$. A polpa integral foi centrifugada a $15000 \mathrm{rpm}(29000 \mathrm{G})$ em uma centrífuga modelo VS - 24 SMT, durante 40 minutos.

\section{Caracterização Físico-Química da Polpa de Manga Centrifugada}

$\mathrm{Na}$ polpa de manga centrifugada foram realizadas as seguintes análises físico-químicas: $\mathrm{pH}$, teor de sólidos solúveis ( ${ }^{\circ}$ Brix), pectina e sólidos insolúveis. As técnicas de análises utilizadas foram de acordo com a metodologia da AOAC (2000), em triplicata.

\section{Medidas Reológicas}

As medidas reológicas foram feitas nas temperaturas de $10,20,30,40,50$ e $60^{\circ} \mathrm{C}$ utilizando o reômetro Haake Rotovisco, modelo RV-20, com sistema de medida de cilindros concêntricos ZA30, o qual é representado na Figura 1. O tempo de corrida, para cada ensaio foi programado para 4 minutos, sendo que nos dois minutos iniciais a taxa de deformação variou de maneira crescente até o valor máximo próximo de $300 \mathrm{~s}^{-1}$. Em seguida, a taxa de deformação variou de maneira decrescente durante dois minutos até o valor mínimo próximo de $0 \mathrm{~s}^{-1}$, com o espaço anular entre os cilindros medindo $1,0 \mathrm{~mm}$.

Tanto na corrida ascendente quanto na descendente foram obtidos 20 pontos de taxa de deformação versus tensão de cisalhamento, resultando num total de 40 pontos, dos quais foi tomado o valor médio da tensão de cisalhamento para cada taxa de deformação. Os experimentos foram realizados em triplicata, onde para cada repetição utilizou-se uma nova amostra, igual a anterior, para evitar possíveis efeitos de tempo.

As curvas de taxa de deformação versus tensão de cisalhamento foram ajustadas pelo modelo Lei da Potência (equação1) e as curvas de viscosidade foram ajustadas pelo modelo de Mizrahi-Berk (equação 2).

$$
\tau=\mathrm{K} \gamma^{\mathrm{n}}
$$

(Equação 1)

em que:

$\tau$ é a tensão de cisalhamento $(\mathrm{Pa}), \gamma$ é a taxa de deformação $\left(\mathrm{s}^{-1}\right), \mathrm{K}$ é o coeficiente de consistência $\left(\mathrm{Pa} \cdot \mathrm{s}^{\mathrm{n}}\right)$ e $\mathrm{n}$ é o índice de comportamento (adimensional), (HAMINIUK et al., 2006).

$$
\tau^{0,5}=\mathrm{K}_{\mathrm{oM}}+\mathrm{K}_{\mathrm{M}} \gamma^{\mathrm{n}_{\mathrm{M}}} \quad \text { (Equação 2) }
$$

em que:

$\tau$ é a tensão de cisalhamento $(\mathrm{Pa}), \gamma$ é a taxa de deformação $\left(\mathrm{s}^{-1}\right), \mathrm{K}_{\mathrm{M}}$ é o coeficiente de consistência $\left(\mathrm{Pa} \cdot \mathrm{s}^{\mathrm{n}}\right)$ e $\mathrm{n}_{\mathrm{M}}$ é o índice de comportamento (adimensional) e $\mathrm{K}_{\mathrm{oM}}$ é a raiz quadrada da tensão inicial de escoamento do fluido (PELEGRINE et al., 2000). 


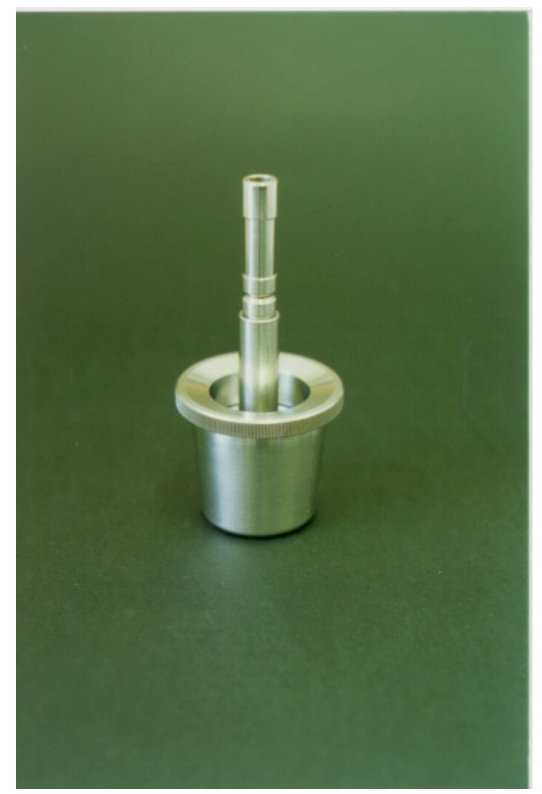

FIGURA 1 - Sistema de medida ZA-30 - Reômetro Haake Rotovisco.

\section{Análise Estatística}

Os dados experimentais (reogramas) foram ajustados pelo modelo da Lei da Potência e as curvas de viscosidade foram ajustados pelo modelo de Mizrahi-Berk utilizando o software ORIGIN 7.0 (OriginLab Corporation, Ma, USA), de acordo com Bender et al. (1982). Os parâmetros estatísticos de $\mathrm{R}^{2}$ e $\mathrm{X}^{2}$ foram obtidos para avaliar a qualidade dos resultados experimentais ajustados ao modelo da Lei da Potência. Neste estudo foi utilizado o delineamento inteiramente casualizado, uma vez que as amostras utilizadas são de um único lote (amostra homogênea).

\section{RESULTADOS E DISCUSSÃO}

\section{Caracterização da polpa}

Os resultados de $\mathrm{pH}$, sólidos solúveis ( $\left.{ }^{\circ} \mathrm{Brix}\right)$, teor de pectina e de sólidos insolúveis determinados para a polpa de manga centrifugada e integral utilizado neste trabalho estão na Tabela 1. Pode-se observar que não houve variação nos valores de $\mathrm{pH}$ e teor de pectina com o processo de centrifugação da polpa integral. No entanto, a polpa centrifugada apresentou uma pequena redução no valor dos sólidos solúveis $(3,31 \%)$. Em relação aos sólidos solúveis, a polpa centrifugada apresentou uma redução de $96,29 \%$, quando comparada com a polpa integral.

Na Figura 2, representa a relação entre tensão de cisalhamento e taxa de deformação para as diferentes temperaturas da polpa de manga centrifugada, respectivamente. Os resultados não indicaram o efeito da tixotropia, apresentando a polpa de manga centrifugada um comportamento não-newtoniano, ocorrendo uma redução progressiva nos valores de tensão de cisalhamento com o aumento da temperatura e diminuição da taxa de deformação.

Comportamentos similares (não-newtoniano) foram obtidos em outros estudos do comportamento reológico de polpas de frutas: Haminiuk et al. (2006), para a polpa integral de araçá; Pelegrine et al. (2002), estudando o comportamento reológico de polpa de abacaxi e manga e Silva et al. (2005) no estudo da reologia de suco de acerola.

$\mathrm{Na}$ Tabela 2 verifica-se que o valor do índice de comportamento (n) apresentou-se menor que um (1) para todos os casos, mostrando que a polpa de manga centrifugada apresenta comportamento reológico pseudoplástico. Com o aumento da temperatura, o índice de comportamento (n) mostrou-se na faixa 0,69 a 0,77 e observase uma diminuição no parâmetro $\mathrm{K}$ (coeficiente de consistência) e um aumento no índice de comportamento $n$.

De acordo com Krokida et al. (2001), o tratamento térmico tem um maior efeito no coeficiente de consistência (K) de fluidos alimentícios não-newtonianos, sendo que o índice de comportamento do fluído (n) é afetado levemente pela temperatura (um pequeno aumento em altas temperaturas).

Comparando os parâmetros reológicos obtidos para a polpa de manga centrifugada (Tabela 2), com os parâmetros reológicos determinados para a polpa de manga integral em estudo realizado por Vidal (2004), pode-se observar o que os sólidos suspensos exercem grande influência no comportamento reológicos desses tipos de polpas.

\section{Viscosidade Aparente}

Pela Figura 3 observou-se, a partir da taxa de deformação de $200 \mathrm{~s}^{-1}$, que a viscosidade aparente tende a ficar constante para as temperaturas de $10^{\circ} \mathrm{C}$ a $60^{\circ} \mathrm{C}$. Os resultados obtidos indicam uma diminuição da viscosidade aparente com o aumento da taxa de deformação até a temperatura de $60^{\circ} \mathrm{C}$, mostrando o comportamento pseudoplástico para a polpa de manga centrifugada, em todas as temperaturas analisadas. Os valores obtidos para índice de comportamento (dados não mostrados) confirmam essa pseudoplasticidade. A temperatura é um dos fatores que mais afeta a viscosidade das polpas de frutas, já que a maioria destas apresenta-se na forma de sólidos dispersos em meios líquidos. Um aumento na temperatura, neste caso, faz com que a viscosidade na fase líquida diminua, aumentando a mobilidade das partículas em suspensão, diminuindo conseqüentemente a viscosidade da polpa. 
TABELA 1 - Características físico-químicas da polpa de manga.

\begin{tabular}{lcc}
\hline \multicolumn{1}{c}{ Parâmetros } & Centrifugada & Integral \\
\hline $\mathrm{pH}$ & 4,47 & 4,47 \\
Sólidos solúveis $\left({ }^{\circ}\right.$ Brix $)$ & 16,05 & 16,60 \\
Pectina (\%) & 0,98 & 0,98 \\
Sólidos insolúveis (g/100 g) & 0,04 & 1,08 \\
\hline
\end{tabular}

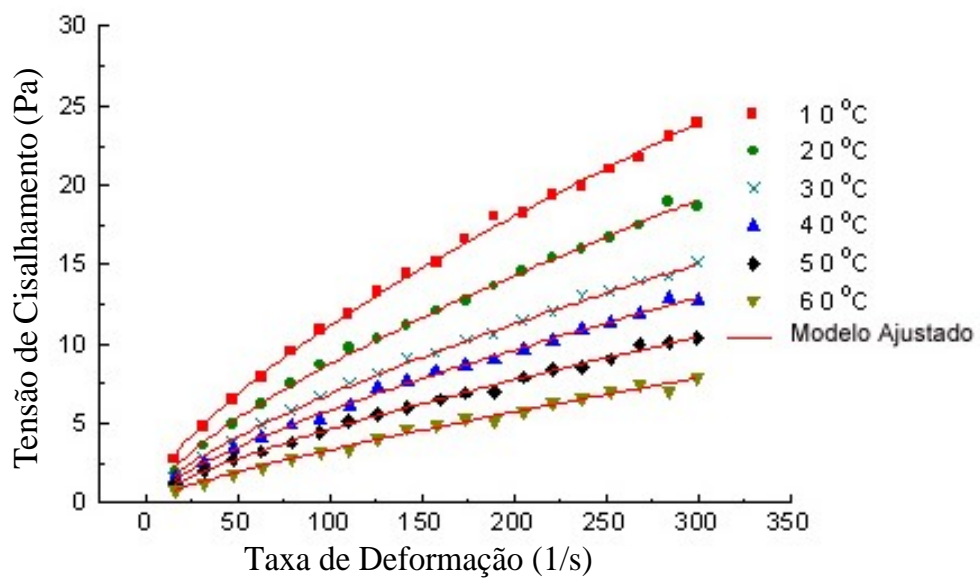

FIGURA 2 - Reograma para a polpa de manga centrifugada ajustado pelo modelo da Lei da Potência.

TABELA 2 - Parâmetros do modelo Lei da Potência para polpa de manga centrifugada.

\begin{tabular}{ccccccc}
\hline \multirow{2}{*}{ Parâmetros } & \multicolumn{7}{c}{ Temperaturas } \\
\cline { 2 - 6 } & $\mathbf{1 0}^{\circ} \mathbf{C}$ & $\mathbf{2 0}^{\circ} \mathbf{C}$ & $\mathbf{3 0}^{\circ} \mathbf{C}$ & $\mathbf{4 0}^{\circ} \mathbf{C}$ & $\mathbf{5 0}^{\circ} \mathbf{C}$ & $\mathbf{6 0}^{\circ} \mathbf{C}$ \\
\hline K $\left(\right.$ Pa.s $\left.^{\mathrm{n}}\right)$ & 0,45 & 0,32 & 0,25 & 0,20 & 0,15 & 0,09 \\
$\mathrm{n}$ & 0,69 & 0,71 & 0,72 & 0,73 & 0,74 & 0,77 \\
Erro K & 0,02 & 0,02 & 0,01 & 0,01 & 0,01 & 0,01 \\
Erro n & 0,00 & 0,01 & 0,00 & 0,01 & 0,01 & 0,02 \\
$\chi^{2}$ & 0,06 & 0,06 & 0,02 & 0,03 & 0,02 & 0,04 \\
$\mathrm{SSR}$ & 1,16 & 1,09 & 0,44 & 0,61 & 0,44 & 0,69 \\
$\mathrm{R}^{2}$ & 0,99 & 0,99 & 0,99 & 0,99 & 0,99 & 0,99 \\
\hline
\end{tabular}

Além disso, os resultados apresentados na Figura 3 estão em concordância com as observações feitas por Giner (1996), ao analisar a influência da temperatura na reologia de suco clarificado de cereja, observando que um aumento na temperatura resultou no decréscimo da viscosidade aparente.
Com a centrifugação, ocorre uma redução acentuada da viscosidade aparente, facilitando o escoamento do suco e a troca de calor durante o processamento. Sabe-se que quanto menor a viscosidade do fluido, menor é a perda de carga durante o escoamento, diminuindo os custos de potência com bombeamento e conseqüentemente os custos energéticos.

Ciênc. agrotec., Lavras, v. 30, n. 5, p. 955-960, set./out., 2006 


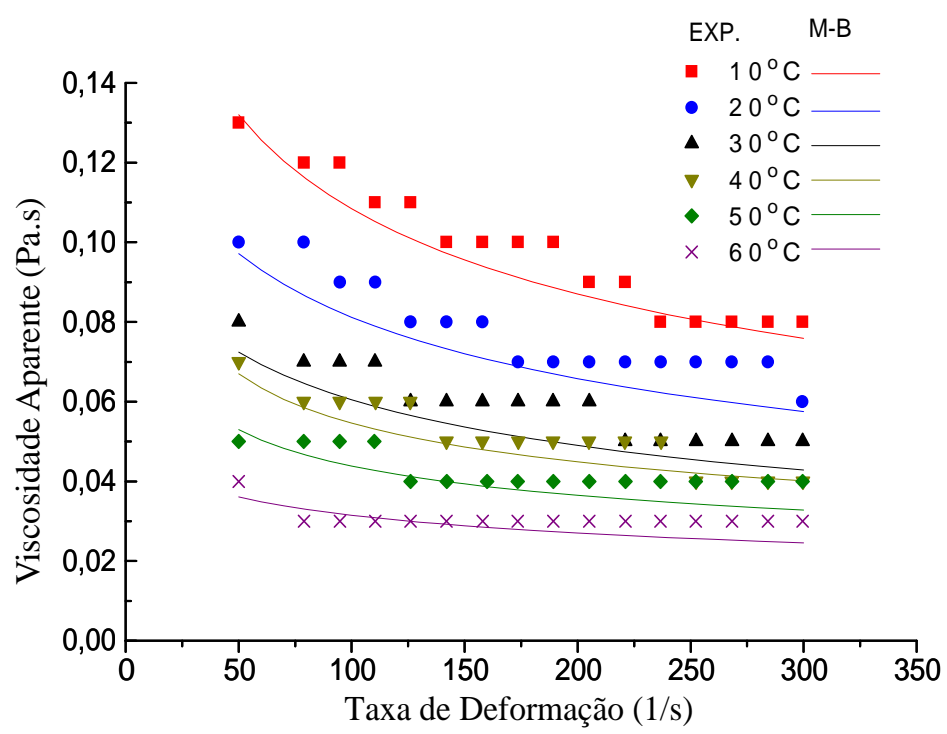

FIGURA 3 - Viscosidade aparente da polpa de manga centrifugada ajustada pelo modelo de Mizrahi-Berk.

\section{CONCLUSÕES}

Para a polpa de manga centrifugada, a viscosidade diminui com o aumento da temperatura até $60^{\circ} \mathrm{C}$, quando se verificou que o índice de comportamento é menor que 1(um), indicando o comportamento pseudoplástico da polpa. Com o aumento da temperatura observou-se um aumento no índice de comportamento (n) e uma diminuição no parâmetro coeficiente de consistência $(K)$, indicando que a polpa de manga centrifugada perde pseudoplasticidade e fica menos viscosa à medida que a temperatura aumenta, facilitando o escoamento e a troca de calor durante o processamento. A partir da taxa de deformação de $200 \mathrm{~s}^{-1}$, a viscosidade aparente tende a ficar constante para as temperaturas de 10 a $60^{\circ} \mathrm{C}$.

\section{REFERÊNCIAS BIBLIOGRÁFICAS}

AHMED, J.; RAMASWAMY, H. S.; HIREMATH, N. The effect of high pressure treatment on rheological characteristics and colour of mango pulp. International Journal of Food Science and Technology, Oxford, v. 40, p. 885-895, 2005.

AHMED, J.; SHIVHARE, U. S.; RAGHAVAN, G. S. V. Rheological characteristics and kinetics of colour degradation of green chilli puree. Journal of Food Engineering, Essex, v. 44, p. 239-244, 2000.

ASSOCIATION OF OFFICIAL ANALYTICAL CHEMISTS. Official methods of analysis. Arlington, 2000.
BHATTACHARYA, S.; RASTOGI, N. K. Rheological properties of enzyme-treated mango pulp. Journal of Food Engineering, Essex, v. 36, p. 249-262, 1999.

BENDER, F. E.; DOUGLASS, L. W.; KRAMER, A. Statistics in research: in statistical methods for food and agriculture. Westport: Avi, 1982.

CEREZAL, P.; BATISTA, A. R.; PIÑERA, R. M. Evaluation de cultivares de mango para la elaboración de pulpas. Alimentaria, [S.1.], v. 260, p. 29-31, 1995.

GINER, J.; IBARZ, A.; GARZA, S.; XHIAN-QUAN, S. Rheology of clarified passion fruit juices. Fruit Processing, Schonborn, v. 6, p. 330-333, 1996.

HAMINIUK, C. W. I.; SIERAKOWSKI, M. R.; VIDAL, J. R. M. B.; MASSON, M. L. Influence of temperature on rheological behavior of whole Araçá pulp (Psidium cattleianum sabine). Lebensmittel-Wissenschaft und Lebensmittel-Wissenschaft und Technologie -Food Science and Technology, Berlin, v. 39, n. 4, p. 427-431, 2006.

HERNANDEZ, E.; CHEN, C. S.; JOHNSON, J.; CARTED, R. D. Viscosity changes in orange juice after ultra-filtration and evaporation. Journal of Food Engineering, Essex, v. 25, p. 387-396, 1995. 
HOLDSWORTH, S. D. Applicability of rheological models to the interpretations of flow and processing behavior of fluid food products. Journal of Texture Studies, [S.I.], v. 2, p. 393-418, 1971.

IBARZ, A.; GONÇALVES, C. A.; EXPLUGAS, S. Rheology of clarified passion fruit juices. Fruit Processing, Schonborn, v. 6, p. 330-333, 1996.

KROKIDA, M. K.; MAROULIS, Z. B.; SARAVACOS, G. D. Rheological properties of fluid fruit and vegetable puree products: compilation of literature data. International Journal of Food Properties, [S.1.], v. 4, n. 2, p. 179-200, 2001.

MANOHAR, B.; RAMKRISHNA, P.; RAMTEKE, R. S. Effect of pectin content on flow properties of mango pulp concentrates. Journal of Texture Studies, [S.1.], v. 21, p. 179-190, 1990.

PELEGRINE, D. H. Comportamento reológico das polpas de manga e abacaxi. 1999. 115 f. Dissertação (Mestrado) Universidade Estadual de Campinas, Campinas, 1999.

PELEGRINE, D. H.; VIDAL, J. R. M. B.; GASPARETTO, C. A. Study of aparent viscosity of mango (Keitt) and pineapple (Pérola) pulps. Ciência e Tecnologia de Alimentos, Campinas, v. 20, n. 1, p. 128-131, 2000.

PELEGRINE, D. H.; SILVA, F. C.; GASPARETTO, C. A. Rheological behavior of pineapple and mango pulps.
Lebensmittel-Wissenschaft und LebensmittelWissenschaft und Technologie Food Science and Technology, Berlin, v. 35, p. 645-648, 2002.

QUEIROZ, A. J. M.; VIDAL, J. R. M.; GASPARETTO, C. A. Influência dos sólidos suspensos na reologia do suco de abacaxi. In: ENCONTRO SOBRE ESCOAMENTO EM MEIOS POROSOS, 14., 1996, Uberlândia, MG. Anais... Uberlândia: UFU, 1996. p. 49-53.

SILVA, F. C. da; GUIMARÃES, D. H. P.; GASPARETTO, C. A. Rheology of acerola juice: effects of concentration and temperature. Ciência Tecnologia Alimentos, Campinas, v. 25, n. 1, p. 121-126, 2005.

SIQUEIRA, D. L.; BROTEL, N.; CARVALHO, V. D.; RAMOS, V. H. V.; COUTO, F. A. D. Características físicas e químicas de vinte cultivares de mangueira (mangifera indica L.). Revista Brasileira de Fruticultura, Cruz das Almas, v. 10, p. 49-54, 1988.

VIDAL, J. R. M. B. Comportamento da polpa de manga (Mangifera indica L. cv. Keitt) integral. Revista Ciências Exatas e Naturais, [S.1.], v. 6, n. 2, p. 217-222, 2004.

VITALI, A. A.; RAO, M. A. Flow properties of low-pulp concentrated orange juice: effect of temperature and concentration. Journal of Food Science, Chicago, v. 49, p. 882-888, 1984. 